\title{
Taylor rules and the Term Structure
}

\author{
Carlo A. Favero ${ }^{a \text {, 来 }}$ \\ ${ }^{a}$ IGIER, Università L. Bocconi, Via Salasco 5, 20124 Milano, Italy and CEPR \\ Received Date; Received in Revised Form Date; Accepted Date
}

\begin{abstract}
The expectations model of the term structure has been subjected to numerous empirical tests and almost invariably rejected, with the failure generally attributed to systematic expectations errors or to shifts in risk premia.Rules for monetary policy designed along the lines of Taylor (1993) specify that the central bank adjusts short-term yields in response to deviations of inflation and output gaps from target level. Such rules give a good empirical account of the behavior of the short-term interest rate.Combining the Taylor rule and expectations theory, it is possible to generate - along lines pioneered by Campbell and Shiller (1987) - a series of theoretical long-term interest rates. When such theoretical rates are calculated for the U.S. over 1980 to 2004, considerable support for the expectations theory emerges.
\end{abstract}

Keywords: Small macroeconomic models, term structure of interest rates, expectations theory

JEL classification: E41, E44, E52

\footnotetext{
*Corresponding author: carlo.favero@unibocconi.it

${ }^{\dagger}$ The title of this paper was originally suggested by Rudi Dornbusch. Of the many priviliges I had in my life, meeting Rudi and working with him was one of the most extraordinary. I would like to thank also Alejandro Cunat, Francesco Giavazzi, Massimo Guidolin, Alessandro Missale, Tommaso Monacelli, Glenn Rudebusch, Guido Tabellini, Luca Stanca, and the participants of seminar at the Federal Reserve Bank of Atlanta, at the Bank of Spain, at ECARES in Brussels, at the EMUConference at the State University of Milan and the Macroeconomic workshop at Bocconi University for helpful comments. I am also indebted to the editor, R.G. King, and an anonymous referee, who provided many very insightful comments and suggestions.

‡The author acknowledges financial support by the Italian Ministry of Research and Education (MIUR) .
} 


\section{Introduction}

The expectations model of the term structure states that the yields to maturity of long term bonds are equal to the average of expected future short-term bond yields. ${ }^{1}$

This venerable model has been subjected to numerous empirical tests and almost invariably rejected ${ }^{2}$, with the failure generally attributed to systematic expectations errors or to shifts in risk premia.

Rules for monetary policy designed along the lines of Taylor (1993) specify that the central bank adjusts short-term yields in response to deviations of inflation and output gaps from target level. Such rules give a good empirical account of the behavior of the short-term interest rate: because (expected) inflation and output gaps are highly persistent, the policy rate is very persistent and forecastable, at least at short horizons. Combining the Taylor rule and expectations theory, it is possible to generate — along lines pioneered by Campbell and Shiller (1987) — a series of theoretical long-term interest rates. When such theoretical rates are calculated for the U.S. over 1980 to 2004, considerable support for the expectations theory emerges, in ways that are discussed further below, which is even stronger than that provided by Campbell and Shiller $(\mathrm{CS})^{3}$.

The analysis in this article has two important implications. First, for economists interested in the pricing of long-term bonds, it shows that the empirical performance of the expectations theory is enhanced by consideration of a macroeconomic model

\footnotetext{
${ }^{1}$ This relation is obtained directly when assuming that expected continously compounded yileds to maturity on all discount bonds are equal (see Fama,1984). It can also be derived as a linear approximation to any of the different non-linear expectations theory of the term structure (see Shiller, Campbell and Schoenholtz, 1983).

${ }^{2}$ See, for example, the textbook treatment in Campbell, Lo, MacKinlay, 1997, Chapter 10, or Patterson, 2000, Chapter 11, )

${ }^{3}$ Recently Bekaert and Hodrick(2000) have argued that the problem leading to the rejection of the theory in CS could be the use of aymptotic inference rather than omitted variables. Their use of small sample distributions of the different VAR based tests leads to much less dramatic rejections than those implied by the aymptotic distribution.
} 
of short-term interest rate determination. Second, for economists interested in monetary policy, including those involved with policy-making in central banks, it reinforces the view that, for economies like the U.S., it is appropriate to use the term structure as a guide to private sector expectations about future monetary policy and that markets understand the general workings of monetary policy as summarized by the Taylor rule. Turning to the details, the article begins by briefly reviewing the CS methodology and highlighting the modification of it used in the paper. It then proceeds to investigating the empirical performance of the term structure model, under the assumption of a Taylor-type interest rate rule.

There are four aspects of the method and the results that are worth highlighting.

First, rather than use a bivariate relationship between short and long rates, as in CS, we study the relation between long-rates of varying horizons and policy rates predicted on the basis of macroeconomic variables, such as inflation and the output gap. If we re-interpret the bivariate VAR of Campbell and Shiller in the light of the success of Taylor rules, it is then clear that considering a bivariate VAR representation is a first step forward from the traditional limited information approach, based on the estimation of single-equation models and on the assumption that realized returns are a valid proxy for expected returns ${ }^{4}$. In a recent paper Elton(1999) clearly asserts that there is ample evidence against the belief that information surprises tend to cancel out over time and hence realized returns can be considered as an appropriate proxy for realized returns. The importance of the effects of expectations errors on the tests of the model are confirmed by a number of papers that relate expectations errors to peso problems or to the very low predictability of short term interest rates (Mankiw and Miron, 1986, Rudebusch, 1995, and Balduzzi et al., 1997). However considering a bivariate model for short-

\footnotetext{
${ }^{4}$ Campbell(1995) shows that high yield spreads fare poorly in predicting increases in long rates, Fama and Bliss(1986) show that the change in yields does not move one-to-one with the forward spot spread, Cochrane(1999) points out that period excess returns on long-term bond are predictable using the information in the forward-spot spread.
} 
term and long-term interest rates is only a first step in that no macroeconomic variables are explicitly included in the information set. A recent strand of the macroeconomic literature has analyzed monetary policy by including the central bank reaction function in small empirical macro model of inflation and output (see, for example, Rudebusch, 2000, Rudebusch and Svensson,1998, 2001, Mc Callum and Nelson, 1999). Fuhrer(1996) uses a simple Taylor-rule type reaction function, the expectations model and reduced-form equations for output and inflation to solve for the reaction function coefficients that delivers long-term rates consistent with the expectations theory to find that modest and smoothly evolving time-variation in the reaction functions parameters is sufficient to reconcile the expectations model with the long-bond data. Fuhrer and Moore(1995) have inserted a term structure equation in a small structural model of the U.S. economy. However, they do not exploit the opportunity for testing the expectations theory. They rather concentrate on explaining the observed correlation between real output and short-term interest rates in terms of the correlation between long-term real interest rates and nominal short-term rates.

Second, a rolling regression technique is used instead of imposing a constantparameters VAR. CS test the restrictions imposed by the ET estimating a VAR model over the full available sample and by using only in-sample information. Such procedure cannot simulate the investors' effort to use the model in 'real time' to forecast future monetary policy rates. In fact, the information from the whole sample is used to estimate parameters while investors can use only historically available information to generate (up to n-period ahead) predictions of policy rates. Moreover, the within sample test understate the uncertainty of agents who forecast policy rates by out-of-sample projections. In this paper the present value framework is used to generate real time forecast for future policy rates. At each point in time a model is estimated, using the historically available information, to project out-of- 
sample policy rates up to the $n$ th-period ahead. Given the path of simulated future policy rates, yield to maturities consistent with the ET are constructed.

Third, using the historically available information on uncertainty, dynamic stochastic simulations are performed to construct confidence bounds around the ETconsistent long-term rates. These bounds reflect explicitly the uncertainty associated with out-of-sample projections. Then, we evaluate the ET by checking if the observed long-term rates fluctuate within the bounds. This procedure allows to evaluate the ET without taking ex-post realized returns as a proxy for ex-ante expected returns, it also allows independent identification of risk-premia from forecast errors about future policy rates.

Fourth, some variant of "efficient markets" forecasting regression is performed with the policy rates projected at different horizons from our forecasting model. The results show that "peso problems" might be quite important in the historical interval that we study. This evidence is also relevant to the recent point made by Rudebusch(2001), who has addressed the issue of the (apparent) contradiction between interest rate persistence in policy rules and low predictability of policy rates to conclude that monetary policy inertia is an illusion.

The paper is organized as follows. Section 2 illustrates how the CS approach can be extended by incorporating a Taylor Rule and rolling regression estimates of expectations. Section 3 applies the methodology to the analysis of the term structure of US interest rates in the nineties. Section 4 concludes.

\section{Evaluating The Expectations Theory.}

The ET is assessed on the relation between long-term yields and policy rates and on a small macroeconomic model relating policy rates to macroeconomic variables. Government bonds are considered as assets whose price is determined by aggregate 
economic information, in fact the price impact of any asset-specific information is considered as negligible. Define the term premium per period rather than over the full life of a bond, then the difference between one-period expected return of a multi-period bond ${ }^{5}$ and the risk-free rate can be written as:

$$
E_{t}\left(p_{t+1, T}-p_{t, T}\right)=i_{t, t+1}+R P_{t, T}
$$

where $p_{t, T}$ is the (log of ) price at time $t$ of a bond with maturity at $T, i_{t, t+1}$ is the one-period return of the policy rates $^{6}, R P_{t, T}$ is the time varying term premium for a bond with maturity $T$. As the relation between $p_{t, T}$ and the continuously compounded return yield to maturity of a bond with maturity $T, i_{t, T}$, is

$$
p_{t, T}=-(T-t) i_{t, T}
$$

we have

$$
i_{t, T}-(T-t-1) E_{t}\left(i_{t+1, T}-i_{t, T}\right)=i_{t, t+1}+R P_{t, T} .
$$

Most empirical tests of the expectations model are based on the estimation of some version of (3)where observed returns are used as a proxy for expected returns.

\subsection{The CS approach}

CS solve forward a linearized version of (3) and impose the null of the ET, to derive the following relation between long-term and short-term interest rates:

$$
\begin{aligned}
i_{t, T}^{*} & =(1-\gamma) \sum_{j=0}^{T-1} \gamma^{j} E_{t}\left[i_{t+j-1, t+j} \mid I_{t}\right] \\
\gamma & =\frac{1}{1+i_{t, T}^{*}}
\end{aligned}
$$

\footnotetext{
${ }^{5}$ We consider zero-coupon bond for the sake of exposition, but the reasoning can be extended to bonds paying coupon

${ }^{6}$ As we consider the policy rate as the safe asset, the period-return of such asset coincides with the yield to maturity.
} 
which could be re-written in terms of spread between long and short-term rates,

$$
\begin{aligned}
S_{t, T}^{*} & =\sum_{j=1}^{T-1} \gamma^{j} E_{t}\left[\Delta i_{t+j-1, t+j} \mid I_{t}\right] \\
S_{t, T} & =i_{t, T}-i_{t, t+1}
\end{aligned}
$$

(6) shows that there is necessary condition for the ET to hold, which puts constraints on the long-run dynamics of the spread; in fact, the spread is stationary, being a weighted sum of stationary variables. Obviously stationarity of the spread implies that, if yields are non-stationary they should be cointegrated with a cointegrating vector $(1,-1)$. However, the necessary and sufficient conditions for the validity of the ET impose restrictions both on the long-run and the short run dynamics.

Having checked that $R_{t, T}$ and $r_{t}$ are cointegrated with a cointegrating vector (1,1), CS construct a bivariate stationary VAR in the first difference of the short-term rate and the spread :

$$
\begin{gathered}
\Delta i_{t, t+1}=a(L) \Delta i_{t-1, t}+b(L) S_{t-1}+u_{1 t} \\
S_{t}=c(L) \Delta i_{t-1, t}+d(L) S_{t-1}+u_{2 t}
\end{gathered}
$$

and test the validity of the ET by testing the exact coefficient restrictions imposed on the distributed lags $a(L), b(L), c(L), d(L)$ by the null $S_{t, T}=S_{t, T}^{*} \cdot{ }^{7}$

Interestingly the Wald test implemented on US data between the fifties and the eighties by Campbell and Shiller (1987) leads to clear rejection of the null of the $\mathrm{ET}^{8}$. However, when CS construct a theoretical spread $S_{t, T}^{\prime}$, by imposing the (rejected) ET restrictions on the VAR they find that, despite the statistical rejection of the ET, $S_{t, T}$ and $S_{t, T}^{\prime}$ are strongly correlated. These findings lead CS to conclude

\footnotetext{
${ }^{7}$ See Campbell-Shiller(1987), page 1167 for an exact derivation of the cross-equation restrictions.

${ }^{8}$ The evidence based on Wald test is confirmed by Sargent(1979) and King and Kurman(2002) by using Likelihood ratio statistics.
} 
that bivariate analysis suggests that there is an important element of truth to the expectations theory of the term structure.

\subsection{Incorporating a Taylor Rule}

We follow an alternative route and use a macro model to derive proxies for expected returns. To illustrate our approach note that, by recursive substitution in(3), we can write:

$$
i_{t, T}=\frac{1}{T-t} \sum_{j=1}^{T} E_{t} i_{t+j-1, t+j}+\frac{1}{T-t} \sum_{j=1}^{T-1} E_{t} R P_{t+j-1, t+T} .
$$

We propose to base forecasts for future policy rates on the arguments of a Taylortype reaction function in which policy rates react to macroeconomic conditions as described by estimates of expected inflation and the output gap. In practice, the following specification is considered:

$$
\left[\begin{array}{c}
\mathbf{Z}_{t} \\
i_{t, t+1}
\end{array}\right]=A_{t}(L)\left[\begin{array}{c}
\mathbf{Z}_{t-1} \\
i_{t-1, t}
\end{array}\right]+\left[\begin{array}{c}
\mathbf{u}_{1 t} \\
u_{2 t}
\end{array}\right]
$$

(9) is a (possibly) time-varying parameter unrestricted VAR in the vector $\mathbf{Z}_{t}$ of macroeconomic variables used by the central bank to assess expected inflation and the output gap and policy rates. This is a general specification which nests the reduced form of structural VARs and small backward-looking and forward-looking macro models. Note that, as we shall use the macro model for forward simulation, we need to concentrate just on the reduced form. The interpretation of the reduced form could be different but different interpretation do not affect the resulting forecast for future short-term policy rate. Consider for example interpreting our VAR as a reduced form of the forward-looking model proposed by Rotemberg and Woodford(1999). The two authors use a VAR representation to estimate the way in which output, inflation and interest rates respond to stochastic disturbances to the monetary policy rule. They then proceed to propose a simple forward-looking 
structure consistent with the VAR reduced form representation. In other words they propose a parsimonious parameterization of a forward-looking model on output and inflation determination, in which the structural parameters are estimated so as to make the model's prediction regarding the effects of monetary policy shock fit those estimated by the unrestricted VAR as closely as possible. This means that the structural model is parameterized in such a way that its forecasts are as close as possible to the VAR based forecasts. Therefore the VAR can be validly used for forecasting purposes even if the true structure is forward-looking. Of course, structural model and reduced form cannot be indifferently used when different policy regimes are simulated, but this is not the relevant problem at hand.

\subsection{Rolling regression estimates of expectations}

Given the general specification of model (9), in each period t, we estimate the VAR using data available up to time t. After rolling estimation, we proceed to stochastic dynamic simulation of the model. The estimation results are used to determine the variance-covariance matrix of the joint normal distribution of the residuals and the mean and the variance-covariance matrix of the estimated parameters, i.e. the stochastic components of the model. The model is then solved repeatedly for different draws of the stochastic components. If coefficient uncertainty is included, then a new set of coefficients is drawn before each repetition. During the repetition, errors are generated for each observation in accordance with the uncertainty associated to all variables. This allows to generate point estimates and confidence interval for all the forecasted variables. The path of model-consistent forecasts is finally used to generate long-term rates under the null of the validity of the pure expectations model as follows:

$$
i_{t, T}^{*}=\frac{1}{T-t} \sum_{j=1}^{T} i_{t+j-1, t+j}^{F}
$$


The relation between $i_{t, T}^{*}$ and $i_{t+j-1, t+j}^{F}$ is deterministic, but the uncertainty on $i_{t+j-1, t+j}^{F}$ is reflected in $i_{t, T}^{*}$. Therefore, point estimates and confidence intervals can be constructed for $i_{t, T}^{*}$ at different maturities. As the model is estimated at monthly frequency, the construction of starred values for the ten-year maturity requires the full path of one-hundred and twenty forecasts for policy rates. Starred valued at shorter horizon are obtained similarly by using the appropriate subset of forecasts. Given that values for $i_{t, T}^{*}$ are obtained under the null hypotheses of no risk premium and model based expectations for future policy rates, our stochastic simulation can be used to evaluate the expectations model. To see this point, combine (8) and (10) to write:

$$
\begin{aligned}
i_{t, T}= & i_{t, T}^{*}+\frac{1}{T-t} \sum_{j=1}^{T}\left(E_{t} i_{t+j-1, t+j}-i_{t+j-1, t+j}^{F}\right) \\
& +\frac{1}{T-t} \sum_{j=1}^{T} E_{t} R P_{t+j-1, t+T}
\end{aligned}
$$

Equation (11) makes clear that deviation of $i_{t, T}$ from $i_{t, T}^{*}$ can be explained by the effect of the risk premia or by differences between model based forecasts, $i_{t+j-1, t+j}^{F}$ and true agents' expectations, $E_{t} i_{t+j-1, t+j}$ Confidence intervals from stochastic simulations are generated under the null that agents form their expectations using our small macro model and the expectations theory holds. If $i_{t, T}$ always falls within such confidence intervals we can conclude that uncertainty on the macroeconomic model does not allow us to reject the null hypothesis. In other words stochastic simulation allows to measure explicitly the range of our ignorance and to assess the extent to which the expectations model can be rejected. Comparison between $i_{t, T}$ and $i_{t, T}^{*}$ at different maturities and assessment of the forecasting errors on macro variables might also shed some light on the relative importance of expectations errors and term premia in explaining deviations of long-term rates from those predicted by the expectations model. 
Before illustrating our application it is important to evaluate this contribution relative to the benchmark of the CS approach.

The approach proposed here differs from CS along several dimensions.

First, CS test the restrictions imposed by the ET estimating a VAR model over the full available sample and by using only in-sample information. Such procedure cannot simulate the investors' effort to use the model in 'real time' to forecast future monetary policy rates, as the information from the whole sample is used to estimate parameters while investors can use only historically available information to generate (up to n-period ahead) predictions of policy rates. Moreover, the within sample test understate the uncertainty of agents who forecast policy rates by outof-sample projections. In this paper the present value framework is used to generate real time forecast for future policy rates. As long-term rates are not included in our estimated model, the ET cross-equation restrictions cannot be imposed. However, at each point in time policy rates are simulated forward to construct long-term rates by imposing the CS type of restrictions on out-of-sample simulated data. Moreover, differently from CS, the validity of restrictions is evaluated by using an out-of-sample measure of uncertainty which gives a better representation of the true uncertainty relevant for economic agents.

Second, consistently with the objective of simulating the real time decision process of agents, a rolling regression approach is adopted, that allows for smoothly time-varying coefficients in the VAR model ${ }^{9}$.

Third, the VAR includes the level of short-term rates and macroeconomic variables. This is because we use the VAR to construct projection of policy rates derived from a Taylor rule, in which monetary policy is determined by (expected) inflation

\footnotetext{
${ }^{9} \mathrm{~A}$ referee pointed out that although are estimated coefficients are revised in real time we use revised data. This objection might be important in the light of the evidence provided by Orphanides(2001)on the impact of monetary policy reaction functions with real-time data. This objection is limited to our measure of the output gap, as the CPI data are not revised. Our evidence is robust to the use of unemployment data, which are not revised, as a cyclical indicator instead of the output gap. Results are available in a companion paper, Carriero et al.(2003)
} 
and the output gap. Stationarity of our VAR is an important issue here. In fact, we consider data only from a period in which the response of monetary policy to inflationary shocks ensures mean-reversion of inflation to the implicit central bank target. So, over our sample covering the Volcker-Greenspan era, the interest rate equation in our VAR is fully equivalent to a Taylor rule and the null that the rank of the long-run coefficients matrix of our VAR is reduced is rejected. The ample evidence that monetary rules were not sufficiently aggressive towards inflation in the seventies implies that our specification in level cannot be adopted for modelling monetary policy before the eighties, and some transformation to induce stationarity in the VAR of the kind considered by CS would indeed be necessary. ${ }^{10}$

\section{The US Term Structure in the Nineties.}

To apply our framework to the analysis of the US term structure we consider a standard specification (Bernanke and Mihov,1998, Rudebusch and Svensson, 1999, Mc Callum and Nelson) of the macroeconomic structure by including in $\mathbf{Z}_{t}$ the $\log$ of the first difference of the IMF world commodity price index, $\operatorname{lpcm}_{t}$, the annual US CPI inflation at time $\mathrm{t}, \pi_{t}$, the US output gap at time $\mathrm{t}, x_{t}$, defined as $\ln \left(X_{t}^{U S}\right)-\ln \left(X_{t}^{U S}\right)^{*}, X_{t}^{U S}$ is the seasonally adjusted industrial production and $\ln \left(X_{t}^{U S}\right)^{*}$ is the Hodrick-Prescott filtered log of industrial productions ${ }^{11}$, we consider the one-month interest rate, $i_{t, t+1}^{U S}$ as the policy rate. We consider data at monthly frequency and estimate a four-lags VAR model ${ }^{12}$ with a rolling procedure starting from the sample 1980:1-1992:1. The choice for the initial sample period

\footnotetext{
${ }^{10}$ Stationarity is very important in our case when we simulate the VAR forward for a very long horizon to derive ET consistent long-rates. The presence of near unit roots would cause the simulated future policy rates to diverge and imply very volatile estimates of the ET consistent long-rates. As a matter of fact, we never obtain divergent rates in any of our simulations.

${ }^{11}$ We use the one-side version of the HP filter built in E-Views with a smoothing parameter set to 14400 .

${ }^{12}$ In fact, when we apply recursively standard lag-selection criteria we find that there are very few occurrencies in which four does not result as an optimal lag. Threfore, we keep the lag of the VAR fixed at four and we neglect uncertainty associated to the selection of the lag length.
} 
is driven by the willingness to consider an homogenous monetary policy-regime in which the stabilizing action of monetary policy renders inflation mean reverting toward the implicit target adopted by the central bank. The empirical evidence in Clarida, Gali and Gertler,1999, 2000 and Favero and Rovelli,2001, supports our sample choice by showing how the Volcker-Greenspan era features an important break in the US monetary policy maker preferences ${ }^{13}$. Estimation is implemented using information on (revised) variables available at the time of the last observation of the sample, hence the output gap is constructed applying the HP filter within the sample considered for estimation.

Importantly, the reaction function implicit in the VAR can be interpreted as reduced form of forward-looking Taylor-type rules.

In fact, the implicit reduced form monetary reaction function in the VAR specification (9) is a projection of current policy rates on past policy rates and on lagged values of macroeconomic variables. This is observationally equivalent to a forward looking Taylor rule in which expected inflation is instrumented by the observed values of macroeconomic variables included in our VAR. Therefore the deviations of monetary authority from the rule should coincide with the VAR residuals. To illustrate this point we have estimated a typical forward-looking Taylor rule using our data over the sample 1987-2001 and compared residuals from this equation with residuals from an estimated $\operatorname{VAR}(4)$ for $l p c m_{t}, \pi_{t},\left(y_{t}-y_{t}^{*}\right), i_{t, t+1}$, over the same sample. VAR-based monetary policy shocks and deviations from the fitted forward-looking rule, feature a correlation of about $0.9^{14}$.

Rolling VAR projections are analyzed in Figure 1 where we report actual values for the commodity prices, CPI inflation, the output gap and policy rates along with

\footnotetext{
${ }^{13}$ The empirical analysis of these papers shows that monetary policy was far less aggressive in fighting inflation in the pre-Volcker era than in the later period, since it was relatively more focused on output stabilization and it allowed real interest rates to decrease in presence of inflationary shocks.

${ }^{14}$ Full results are available on request.
} 
forecasts up to 120-steps ahead taken at different sample points

\section{Insert Figure 1 here}

The comparison of forecasts with realized values for all variables confirms the presence of persistence in forecasting errors. Forecasting errors are small at very short horizon, then they increase with maturity but eventually they decrease again with maturity. Forecasting errors at longer horizon are smaller than forecasting errors at shorter horizon, as the model seem to deliver good (time-varying) estimates for the long-run equilibria of all variables but does not perform as well in describing the short-term dynamic adjustments towards equilibria.

Further insight on the sources of uncertainty and on its importance for our results can be gained by analyzing the forecasting performance of our small macro model for policy rates at different future horizons. We report in Figure 2 actual policy rates at time $\mathrm{t}$ with predicted policy, based on model simulation run at time $t-j$, with $\mathrm{j}=1,6,12,24$, months. Table 2 reports the results of the estimation of the following predictive regression:

$$
i_{t, t+1}=\hat{\beta}_{0}+\hat{\beta}_{1 t-j} i_{t, t+1}^{F}+\hat{u}_{t}
$$

where $t_{t-j} i_{t, t+1}^{F}$ is the model based prediction for $i_{t, t+1}$ based on the information set available at time $t-j$.

\section{Insert Figure 2 and Table 1 here}

The graphical and the econometric evidence show clear an hump-shape pattern in the performance of the model to forecast future policy rates. The model does very well at short horizons: the null $\hat{\beta}_{0}=0, \hat{\beta}_{1}=1$ cannot be rejected for the 1 -month and the 3 -month horizon and the $\mathrm{R}^{2}$ from these regression is respectively of 0.96 and 0.88. However the forecasting performance deteriorates rapidly with estimates of $\hat{\beta}_{0}$ becoming increasingly higher and more significant and estimates of $\hat{\beta}_{1}$ becoming 
increasingly lower and less significant. The worst results for the predictive regressors are obtained for the 1-year horizon where $\hat{\beta}_{0}=3.18, \hat{\beta}_{1}=0.33$ and the $\mathrm{R}^{2}$ from the predictive regression is 0.06 . Interestingly, the performance of the predictive regressions improves again for forecasting horizons higher than 1-year: at the threeyear horizon $\beta_{0}$ is again not significantly different from zero, $\beta_{1}=0.60$ and the $\mathrm{R}^{2}$ is 0.17

This evidence makes clear that realized returns are a very bad proxy for expected returns, when expectations are formed using our macro model. Moreover, the pattern of expectations error allows to rationalize the time-series behavior of the difference between actual, $i_{t, T}$, and simulated, $i_{t, T}^{*}$ in terms of the expectations model. This evidence also supports the explanation, based on the pattern of forecasts errors, of the results of single-equation tests of the expectations model based on the regression of yield spreads on future short rate changes ${ }^{15}$

The results of our regressions in Table 1 are also comparable with the empirical results recently provided by Rudebusch(2001). Rudebusch runs predictive regressions using expected policy rates implicit in Federal Funds future contracts. Given the availability of future contracts, he considers forecasting horizons up to nine months to obtain results very similar to ours. The very low predictability of policy rates at the six-months and the nine-months horizon is taken as a strong argument supporting the conclusion that monetary policy inertia is an illusion.

Importantly, the fact that the predictive regressions based on model projections and Federal Fund future give very similar results does not contradict the assumption that there is no major discrepancy between the information set used by agents and that implicit in our econometric specification. However, our results are against

\footnotetext{
${ }^{15}$ In commenting this type of regression Campbell, Lo and McKinley(1997,p.423) state

"... The U-shaped pattern of regression coeffcients in Table 10.3 may be explained by reduced forecastability of interest rates movements at horizons around one-year. There may be some short-run forecastability arising from Federal Reserve operating procedures, and some long-run forecastability arising from business-cycle effects on interest rates..."
} 
the conclusion that monetary policy inertia is an illusion. In fact, we predict policy rates using a model which features strong persistence and we still find very little predictability for policy rates at horizons between six-months and one-year. Persistence is only a necessary conditions for predictability of policy rates when they are set according to a rule which react to macroeconomic conditions. In this case stability of the rule, precision in the estimation of parameters, and predictability of macroeconomic conditions are required along with persistence to generate predictability. Our model-based simulations suggest that these conditions do not occur at frequencies between six-months and one-year. Interestingly, predictability improves notably for horizons higher than one-year where business-cycle and its effects on interest rates become more predictable.

\subsection{Evaluating the Term Structure Model}

Given the results of the rolling estimation of the VAR, the variance covariancematrix of the estimated residuals is retrieved and the model is stochastically simulated for an horizon up to one-hundred and twenty observations to generate observation in 1992:1 for $i_{t, T}^{*}$, with $T=3,6,12,24,36,50,84,120$. Starred variables and their confidence intervals are then to be compared with observed yields to maturity ${ }^{16}$. We then shift the horizon forward by one period, re-estimate the VAR over the sample 1980:1-1992:1 to re-run our stochastic simulation and construct starred variables in 1992:1 and their associated confidence intervals. The procedure is repeated until the last sample for estimation is 1990:5-2002:05 for a total of 125 model estimation and simulation.

We report in Figures 3-4 the time-series of 125 observations on $i_{t, T}^{*}$, the associated two standard errors confidence intervals and $i_{t, T}$, with $T=3,6,12,24,36,50,84,120$. Starred variables and the uncertainty surrounding them are recursively obtained fol-

\footnotetext{
${ }^{16}$ All the macroeconomic time-series are taken from DATASTREAM, while interest rates at all maturities are taken from the FRED database at the website of the Federal Bank of St.Louis.
} 
lowing the procedure described in the previous section with stochastic simulations based on one-thousand replications for each sample points. ${ }^{17}$

\section{Insert Figures 3-4 here}

The Figures show clearly that the uncertainty on the macroeconomic structure does not allow rejection of the expectations model at all sample points and at all frequencies. Moreover, there is a clear tendency for the observed interest rates to co-move with the simulated interest rates at the mid-point of the 95 per cent confidence interval. Clearly, the 95 per cent confidence intervals get larger as the maturity of the relevant interest rate gets longer, but the observed interest rates get nowhere near the upper and the lower band. On the basis of this evidence we can conclude that the expectations theory tracks shorter and long-term maturities rather well.

It is interesting to consider the time-series behavior of the difference between actual, $i_{t, T}$, and simulated, $i_{t, T}^{*}$, series, which, according to equation (11) depend on risk premia and on the differences between model based forecasts and agents' expectations.

We report in Table 2 the statistical properties of these time-series organized by maturity.

\section{Insert Table 2 here}

The statistics indicate that the average, taken over the whole simulation sample, of the difference between actual and simulated yields is zero at the three-month maturity, than it becomes negative with a declining pattern to reach a minimum -29 basis points at the 2-year maturity, from the three-year maturity onward the pattern becomes increasing to reach a positive value of 16 basis points at the 7-year maturity

\footnotetext{
${ }^{17}$ The recursive simulation procedure based on the rolling estimation of the VAR has been implemeted in E-Views 4. Programmes and the original data-set are available from the author's upon request
} 
and a maximum of 20 basis points in correspondence of the 10-year maturity. Given that risk premia cannot be negative, consistency of this evidence with equation (11) requires that deviations of simulated from actual variables reflect persistent expectations error for policy rates. The relative importance of the expectations errors should be hump-shaped, reaching a peak between the one-year maturity and the two-year maturity. Interestingly, this pattern is consistent with the results of the predictive regressions reported in Table 1.

We believe that the main reason for the difference between these results and those available in the previous literature lies in the fact the vast majority of the empirical evidence is based on the estimation of single-equation models and on the assumption that realized returns are a valid proxy for expected returns. To illustrate the point we have considered the 1-year maturity and derived the yields to maturity consistent with the expectations model by using our approach (we label the resulting rates ex-ante) and by averaging ex-post observed policy rates, and by therefore assuming no expectations error (we label the resulting rates ex-post).

We report in Figure 3 the actual 1-year rates along with the ex-ante and ex-post rates and the confidence intervals from our simulations.

\section{Insert Figure 3 here}

A number of remarks are in order. First, as originally observed by Shiller(1979), the actual rates are more volatile than the ex-post rates. However, the reverse is true for the ex-ante rates, which are more volatile than the actual. Therefore, expectations errors play an important role in the rejection of the expectations theory based on the assumption that realized returns are a valid proxy for expected returns. Moreover, while the observed one-year rate is always within the 95 per cent confidence interval generated by our simulation, the same is not true for the ex-post rates. This is interesting in that it shows that our approach has (at least) the power to reject testing methods based on limited information. 


\section{Conclusions}

A new framework for the assessment of the validity of the expectations model of the term structure of interest rates is proposed. The evaluation of the ET is based on the information generated by macro variables included in Taylor-type reaction functions. This approach differs from the limited information one taken commonly in the literature in that the future path of policy rates is derived consistently with a central bank reaction function rather than by taking realized returns as a proxy for expected returns. The empirical results show that the combination of a Taylor rule and the Expectations Theory tracks short-term and long-term yields to maturity rather well. Moreover, the different performance of the expectations model at different maturities can be explained by the different performance of the estimated VAR for macroeconomic variables in capturing the dynamics of policy rates at different forecasting horizons.

Model based expectations are volatile and expectations errors are sizeable and persistent. These results are capable of explaining why observed yield to maturity are too volatile with respect to theoretical yields obtained by using ex-post realized returns as a proxy for expected returns.

Model-projected long-term rates feature sizeable uncertainty, as the forward projections of policy rates depend both on the uncertainty on monetary policy and on its macroeconomic determinants. However, the predictive regressions for policy rates based on model projections give very similar results to those based on Federal Fund futures. The performance of the model for the prediction of policy rates is hump-shaped with evidence of predictability at short and long horizons but no evidence for predictability at horizons around the one-year. This evidence matches the hump-shape profile of the discrepancies between actual yield and simulated yields as a function of maturity. Finally, given that policy rates are predicted by using a model which features strong persistence, low predictability at horizons around 
one-year does not necessarily imply that interest rate smoothing is an illusion.

\section{References}

Balduzzi P., Bertola G., and Foresi S., 1997. A model of target changes and the term structure of interest rates. Journal of Monetary Economics, 24, 371-399.

Bekaert G. and R.J. Hodrick, 2000. Expectations hypotheses tests. NBER Working Papers 7609, National Bureau of Economic Research

Bernanke, B. S. and Mihov, I.,1998. Measuring monetary policy. Quarterly Journal of Economics, 113, 3: 869-902.

Campbell J.,1995. Some Lessons from the Yield Curve. Journal of Economic Perspectives, 9(3), 129-152.

Campbell J., A. Lo and C.Mackinlay, 1997. The Econometrics of Financial Markets. Princeton University Press: Princeton

Campbell J.Y. and Shiller R.J., 1987. Cointegration and Tests of Present Value Models. Journal of Political Economy, 95, 1062-1088

Campbell J.Y. and Shiller R.J., 1991.Yield Spreads and Interest Rate Movements: A Bird's Eye View. The Review of Economic Studies, 58, 3, 495-514

Carriero A., C.A. Favero and I Kamynska,. 2004. Financial Factors, Macroeconomic Information and the Expectations Theory of the Term Structure of Interest Rates. CEPR discussion paper DP4301

Clarida R., J. Galì and M. Gertler, 1998. Monetary policy rules in practice:some international evidence. European Economic Review, 42,

Clarida R., J. Galì and M. Gertler,1999. The science of monetary policy: A newKeynesian perspective. Journal of Economic Literature, XXXVII (4), 16611707. 
Clarida R., J. Galì and M. Gertler, 2000. Monetary policy rules and macroeconomic stability: evidence and some theory. The Quarterly Journal of Economics, 115, 1, 147-180

Elton E.J,1999. Expected return, realized return and asset pricing tests. Journal of Finance, 54, 4, 1199-1220

Eviews4, 2001. User's guide, Quantitative Micro Software, LLC

Fama E., 1984. The Information in the Term Structure. Journal of Financial Economics, 13, 509-528

Fama E., and R.R. Bliss, 1987. The Information in Long-Maturity Forward Rates. American Economic Review, 77, 680-692

Favero C.A., and R.Rovelli, 2003..Macroeconomic stability and the preferences of the Fed. A formal analysis, 1961-98, Journal of Money, Credit and Banking, $35,4,545-556$

Fuhrer J.C. and G.R. Moore,1995. Monetary Policy Trade-offs and the Correlation between Nominal Interest Rates and Real Output., The American Economic Review, 85, 1, 219-239

Fuhrer J.C.,1996. Monetary Policy Shifts and long-term interest rates. The Quarterly Journal of Economics, 111, 4, 1183-1209

King R.G. and A.Kurmann, 2002. Expectations and the term Structure of Interest Rates: Evidence and Implications. Richmond Fed Quarterly

Mankiw N.G. and J.Miron ,1986 . The changing behaviour of the term strucutre of interest rates.,The Quarterly Journal of Economics, 101, 211-221 
Mc Callum B.T. and E. Nelson, 1999a. Performance of Operational Policy Rules in an Estimated Semiclassical Structural Model. in John B. Taylor (ed.), Monetary Policy Rules, University of Chicago Press

Mc Callum B.T. and E.Nelson, 1999b. An Optimizing IS-LM specification for monetary policy and business cycle analysis. Journal of Money Credit and Banking, 31, 296-317

Patterson K.,2000. An Introduction to Applied Econometrics. A Time-series approach.Palgrave

Rotemberg J.J. and M.Woodford,1999 . An optimization-based econometric framework for the evaluation of monetary policy. Brookings Paper on Economic Activity, 297-361

Rudebusch G.D.,1995. Federal reserve interest rate targeting, rational expectations, and the term structure. Journal of Monetary Economics, 35, 245-274.

Rudebusch G.D.,2000. Assessing Nominal Income Rules for Monetary Policy with Model and Data Uncertainty. paper available from the website www.sffrb.org/ economists /grudebusch

Rudebusch G.D. and L.E.O. Svensson,1999. Policy Rules for Inflation Targeting. In John B. Taylor (ed.), Monetary Policy Rules, University of Chicago Press

Rudebusch G.D,.2001.Term Structure Evidence on Interest Rate Smoothing and Monetary Policy Inertia, paper available from the website www.sffrb.org/ economists /grudebusch

Sargent T.J., 1979. A note on MLE of Rational Expectations Model of the Term Structure. Journal of Monetary Economics, 5,1, 133-143 
Shiller R.J.,1979. The Volatility of Long-Term Interest Rates and Expectations Models of the Term Structure. The Journal of Political Economy, 87,6, 11901219

Shiller R.J., Campbell J.Y. and Schoenholtz, K.L.,1983. Forward rates and Future Policy: Interpreting the Term Structure of Interest Rates. Brookings Papers on Economic Activity, 1, 173-217

Soderlind P. and L.Svensson 1997. New techniques to extract market expectations from financial instruments. Journal of Monetary Economics, 40, 383-429

Taylor J.B., 1993. Discretion versus policy rules in practice. Carnegie-Rochester Conference Series on Public Policy, 39, 195-214 
Table 1: Predictive regressions for the US monetary policy rate.

Sample 1995:1 2002:5

\begin{tabular}{lccccc}
\hline \hline & $\beta_{0}$ & $\beta_{1}$ & $R^{2}$ & DW & S.E: \\
\hline $\mathrm{j}=1$ months & $\begin{array}{c}0.12 \\
(0.11)\end{array}$ & $\begin{array}{c}0.97 \\
(0.02)\end{array}$ & 0.96 & 1.80 & 0.24 \\
$\mathrm{j}=3$ months & $\begin{array}{c}0.32 \\
(0.18)\end{array}$ & $\begin{array}{c}0.90 \\
(0.035)\end{array}$ & 0.88 & 0.66 & 0.43 \\
$\mathrm{j}=6$ months & $\begin{array}{c}0.60 \\
(0.34)\end{array}$ & $\begin{array}{c}0.80 \\
(0.06)\end{array}$ & 0.64 & 0.28 & 0.74 \\
$\mathrm{j}=9$ months & $\begin{array}{c}0.95 \\
(0.68)\end{array}$ & $\begin{array}{c}0.70 \\
(0.11)\end{array}$ & 0.31 & 0.12 & 1.02 \\
$\mathrm{j}=12$ months & $\begin{array}{l}3.18 \\
(0.87)\end{array}$ & $\begin{array}{c}0.33 \\
(0.14)\end{array}$ & 0.06 & 0.06 & 1.20 \\
$\mathrm{j}=24$ months & $\begin{array}{c}2.66 \\
(0.87)\end{array}$ & $\begin{array}{c}0.40 \\
(0.13)\end{array}$ & 0.09 & 0.06 & 1.18 \\
$\mathrm{j}=36$ months & $\begin{array}{c}1.30 \\
(0.92)\end{array}$ & $\begin{array}{c}0.60 \\
(0.14)\end{array}$ & 0.17 & 0.07 & 1.13 \\
\hline \hline
\end{tabular}

The estimated model is $i_{t, t+1}=\beta_{0}+\beta_{1 t-j} i_{t, t+1}^{F}+\hat{u}_{t}$, where $t_{t-j} i_{t, t+1}^{F}$ is the model based prediction for $i_{t, t+1}$ based on the information set available at time $t-j$. 


\begin{tabular}{|c|c|c|c|c|c|c|c|c|}
\hline Maturity & $3-\mathrm{m}$ & $6-\mathrm{m}$ & $1-y$ & $2-y$ & $3-y$ & $5-y$ & $7-y$ & $10-y$ \\
\hline Mean & 0.008 & -0.02 & -0.05 & -0.29 & -0.21 & -0.02 & 0.16 & 0.20 \\
\hline Std. Dev. & 0.20 & 0.37 & 0.59 & 0.72 & 0.81 & 0.82 & 0.77 & 0.70 \\
\hline Skewness & -0.28 & -0.33 & -0.28 & -0.45 & -0.42 & -0.33 & -0.24 & -0.18 \\
\hline Kurtosis & 4.64 & 3.04 & 2.45 & 2.40 & 2.17 & 2.15 & 2.17 & 2.15 \\
\hline Correlations & $3-\mathrm{m}$ & $6-\mathrm{m}$ & $1-y$ & $2-\mathrm{y}$ & $3-\mathrm{y}$ & $5-\mathrm{y}$ & $7-y$ & $10-y$ \\
\hline $3-\mathrm{m}$ & 1.0 & 0.91 & 0.82 & 0.70 & 0.65 & 0.57 & 0.56 & 0.46 \\
\hline $6-\mathrm{m}$ & & 1.0 & 0.96 & 0.84 & 0.80 & 0.71 & 0.68 & 0.58 \\
\hline $1-y$ & & & 1.0 & 0.93 & 0.89 & 0.82 & 0.79 & 0.68 \\
\hline $2-y$ & & & & 1.0 & 0.98 & 0.93 & 0.91 & 0.84 \\
\hline $3-y$ & & & & & 1.0 & 0.98 & 0.96 & 0.91 \\
\hline $5-y$ & & & & & & 1.0 & 0.99 & 0.97 \\
\hline $7-y$ & & & & & & & 1.0 & 0.98 \\
\hline $10-y$ & & & & & & & & 1.0 \\
\hline
\end{tabular}


Figure 1: Actual and forecasted US series
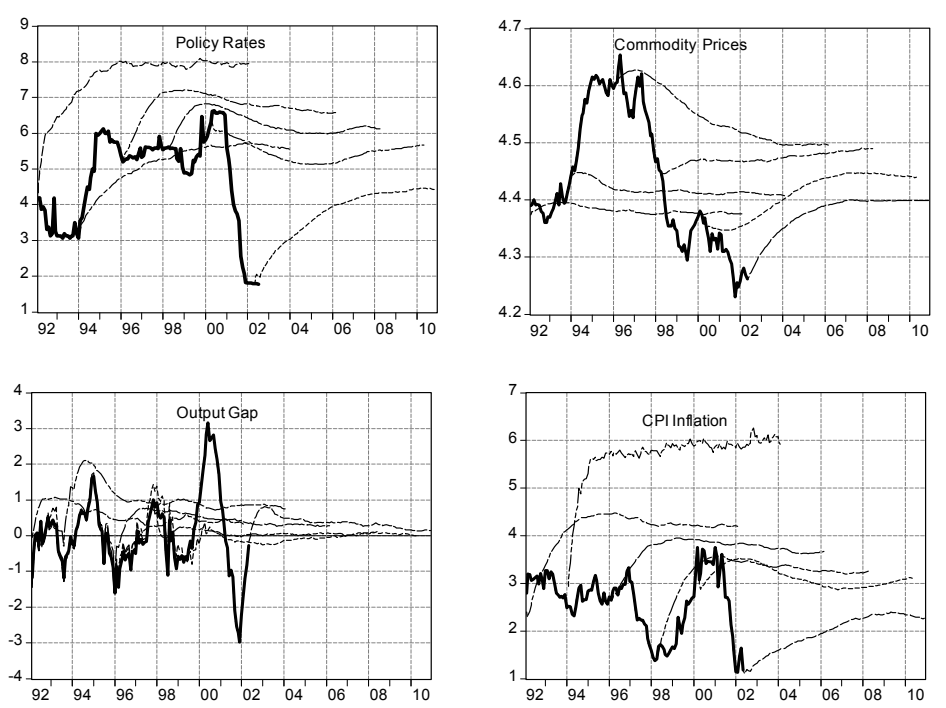

The figure reports actual values for the series in the VAR along with forecasts up to 120 -steps ahead taken at different sample points. 
Figure 2: Model based predictions for US monetary policy rates.
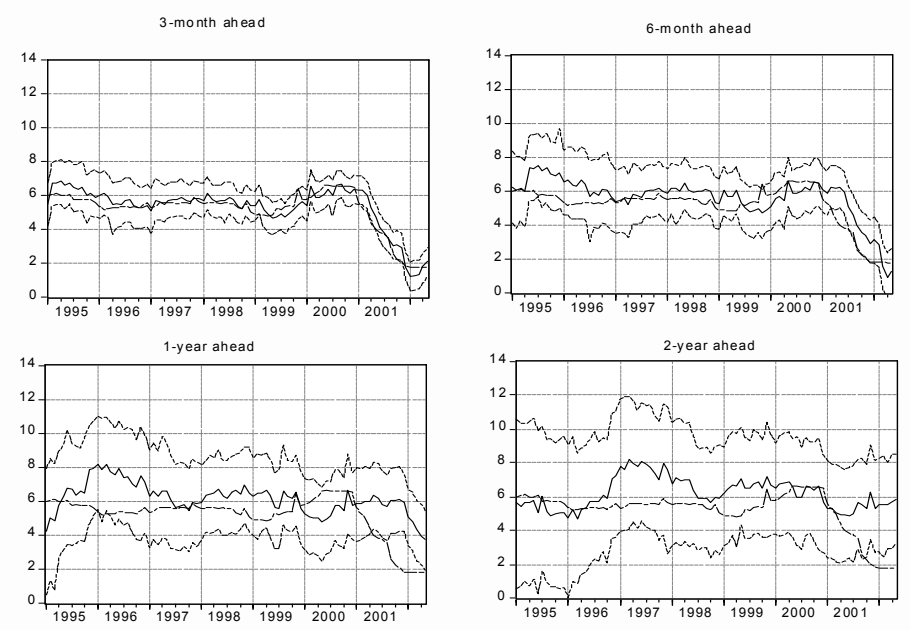

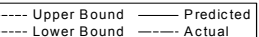


Figure 3: Actual and simulated interest rates for shorter maturities.
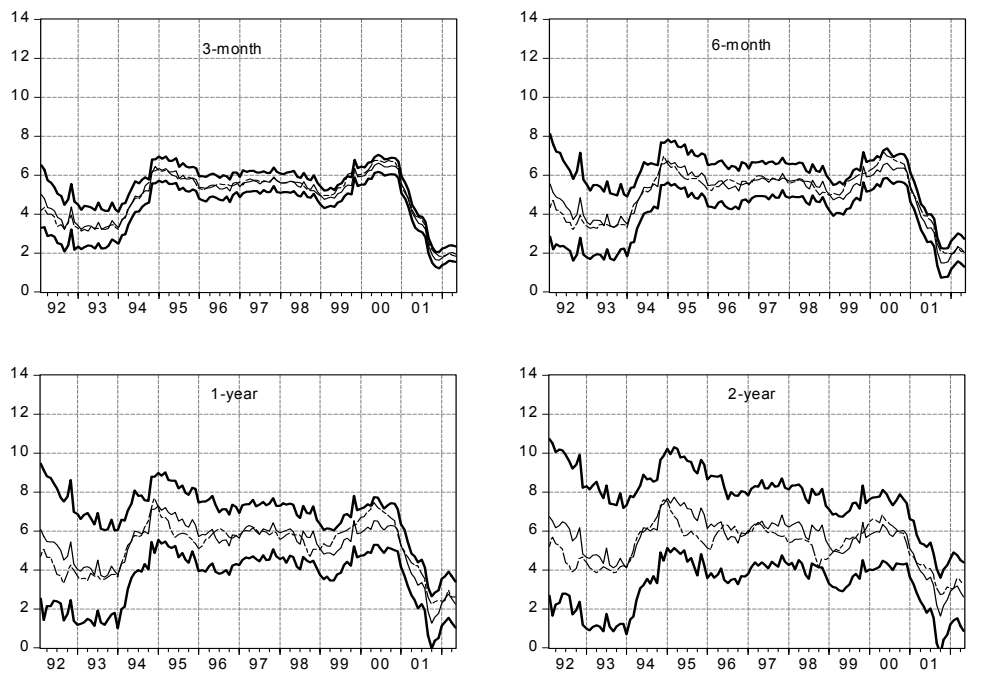

- Simulated $=$ Lower

Simulation are stochastic so actual and (average) simulated rates are reported with upper and lower bounds of their ninety-five per cent confidence interval. 
Figure 4: Actual and simulated interest rates for longer maturities.
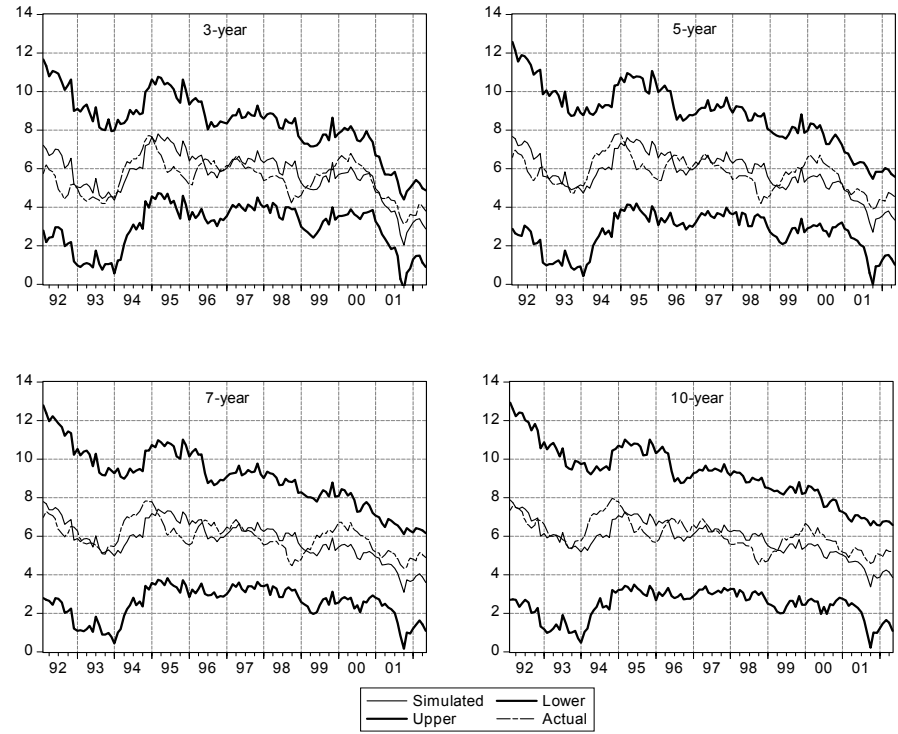

Simulation are stochastic so actual and (average) simulated rates are reported with upper and lower bounds of their ninety-five per cent confidence interval. 
Figure 5: Simulated ex-ante and ex-post 1-year yields to maturity
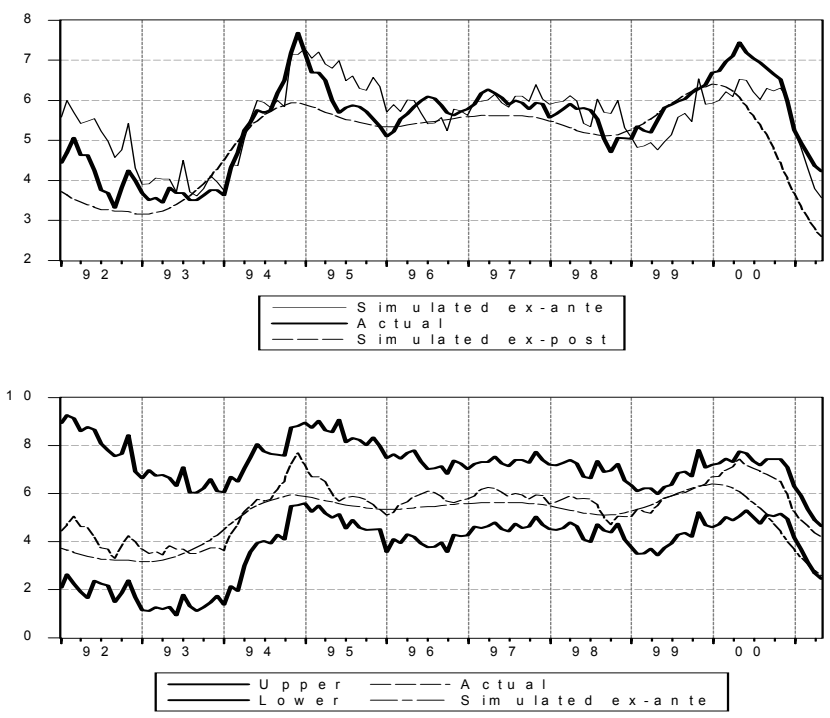

Actual 1-year rates, with simulated ex-ante(model based) rates, simulated expost rates (average of actual policy rates), and upper and lower bounds of the confidence intervals of simulated rates. 